\title{
Contemplating stem cell therapy for epilepsy-induced neuropsychiatric symptoms
}

This article was published in the following Dove Press journal:

Neuropsychiatric Disease and Treatment

23 February 2017

Number of times this article has been viewed

\section{Gautam Rao \\ Sherwin Mashkouri \\ David Aum \\ Paul Marcet \\ Cesar V Borlongan}

Department of Neurosurgery and Brain Repair, Center of Excellence for Aging and Brain Repair, University of South Florida Morsani College of Medicine, Tampa, FL, USA
Correspondence: Cesar V Borlongan Center of Excellence for Aging and Brain Repair, Department of Neurosurgery and Brain Repair, University of South Florida Morsani College of Medicine, I290I Bruce B Downs Blvd, MDC 78, Tampa, FL 33612, USA

$\mathrm{Tel}+\mathrm{I} 8139743154$

Fax+l 8I39743078

Email cborlong@health.usf.edu
Abstract: Epilepsy is a debilitating disease that impacts millions of people worldwide. While unprovoked seizures characterize its cardinal symptom, an important aspect of epilepsy that remains to be addressed is the neuropsychiatric component. It has been documented for millennia in paintings and literature that those with epilepsy can suffer from bouts of aggression, depression, and other psychiatric ailments. Current treatments for epilepsy include the use of antiepileptic drugs and surgical resection. Antiepileptic drugs reduce the overall firing of the brain to mitigate the rate of seizure occurrence. Surgery aims to remove a portion of the brain that is suspected to be the source of aberrant firing that leads to seizures. Both options treat the seizure-generating neurological aspect of epilepsy, but fail to directly address the neuropsychiatric components. A promising new treatment for epilepsy is the use of stem cells to treat both the biological and psychiatric components. Stem cell therapy has been shown efficacious in treating experimental models of neurological disorders, including Parkinson's disease, and neuropsychiatric diseases, such as depression. Additional research is necessary to see if stem cells can treat both neurological and neuropsychiatric aspects of epilepsy. Currently, there is no animal model that recapitulates all the clinical hallmarks of epilepsy. This could be due to difficulty in characterizing the neuropsychiatric component of the disease. In advancing stem cell therapy for treating epilepsy, experimental testing of the safety and efficacy of allogeneic and autologous transplantation will require the optimization of cell dosage, delivery, and timing of transplantation in a clinically relevant model of epilepsy with both neurological and neuropsychiatric symptoms of the disease as the primary outcome measures.

Keywords: epilepsy, neuropsychiatric, stem cells, autologous

\section{Epilepsy - a disorder of the brain and the mind}

Epilepsy is a neurologic disorder that is characterized by having two or more unprovoked recurrent seizures due to abnormal brain activity. ${ }^{1-3}$ This complex disease consists of many syndromes, diagnostic criteria, and treatment strategies. ${ }^{4-6}$ Sixty million people are affected by epilepsy worldwide. ${ }^{7}$ In the US, epilepsy affects $\sim 2.3$ million and costs the health care system $\$ 15.5$ billion either directly, through medically related costs, or indirectly, through loss of productivity. ${ }^{8}$ Also, $\sim 30 \%$ of epileptic patients have temporal lobe epilepsy (TLE) which is characterized by complex partial seizures, limbic degeneration specifically in the hippocampus, and comorbid psychiatric disorders. ${ }^{9-11}$ There are two main classifications of seizures as stated by the International League Against Epilepsy, namely, generalized seizures and focal seizures. Generalized seizures are typically bilateral, rapidly occurring, and originate at a single point. Subtypes of generalized seizures include: tonic-clonic, absence, myoclonic, clonic, tonic, and atonic. Focal seizures originate in one hemisphere and can be either localized in that one area or distributed to other areas. ${ }^{12}$ 
There are three main classifications of epilepsy diagnosis: genetic, structural/metabolic, and unknown cause. Genetic epilepsy is caused by a direct genetic defect that causes seizures as one of the primary symptoms. Structural/metabolic epilepsy is caused by a distinct structural lesion or a metabolic disease that is the root cause of seizures. Examples of structural/metabolic type include traumas such as strokes or infections that lead to seizures. Unknown cause epilepsy is not meant to be similar to idiopathic. Instead, it means that there could be a genetic component or it may be due to another disease, but the underlying cause of the seizures is unknown at the current time. ${ }^{12}$

Epilepsy also presents with cognitive and behavioral deficits that are typically seen in patients with classic neuropsychiatric disorders. These deficits include: hallucination, change in affect, delusion, apathy, changes in cognition, and delirium, to name a few. ${ }^{13,14}$ People with epilepsy also share comorbidities with neuropsychiatric disorders such as anxiety, depression, and obsessive compulsive disorder. ${ }^{15,16}$ Epilepsy has been known for millennia. From the time before Hippocrates, epilepsy and its symptoms have been attributed to extra-worldly causes, as seen in its depiction in famous paintings and novels..$^{17,18}$

The current treatment options for epilepsy are pharmacologic drugs (ie, antiepileptic drugs [AEDs]) and surgery. AEDs are the primary method of treatment, and function by reducing the overall firing of the brain by inhibiting sodium and other positive ion channels or by activating gamma-Aminobutyric acid (GABA)ergic channels. ${ }^{19}$ Surgical resection of the temporal lobe is an option when AED treatment fails, and involves partial removal of the seizuregenerating brain tissue in order to manage symptoms..$^{20}$ Most treatments focus on controlling the neurological aspect of epilepsy, but fail to address the neuropsychiatric component. AEDs do help with the neuropsychiatric components indirectly by attenuating neural firing and essentially shutting off pathways that are present. ${ }^{14}$ Deep brain stimulation is another treatment option that indirectly treats the neuropsychiatric component of epilepsy by altering the firing of the limbic areas. ${ }^{21}$ Additional research is necessary to find a treatment option that ameliorates both the neurological and neuropsychiatric components of epilepsy. Stem cell therapy has emerged as an experimental treatment for a number of neurological and neuropsychiatric disorders. For epilepsy, the goal of stem cell therapy is to enhance stem cell differentiation and growth toward the GABAergic lineage in order to rewire the GABA-deficient neural circuitry seen in epilepsy. ${ }^{9}$ This therapy has been reported for treating other neurological disorders, such as Parkinson's disease and multiple sclerosis, and neuropsychiatric diseases, such as depression and schizophrenia. ${ }^{22}$ These encouraging results may be extrapolated to include treatment of epilepsy which has both neurological and neuropsychiatric components. ${ }^{23,24}$ In this article, we present in detail the current and emerging treatments of epilepsy, noting the potential of stem cell transplantation, as well as highlighting the gap in knowledge relating to the neglected neuropsychiatric aspect of the disease that will likely direct the treatment indications for epilepsy in future.

\section{Epilepsy: mind over matter}

Defining epilepsy as a neurological disorder allows one to understand that it has a physiological basis in the human brain, characterized by a very real and measureable hyperactive neurological etiology. Because of the ethical dilemmas associated with studying brain tissue in human epileptics, many preclinical models of epilepsy have contributed to our understanding of epilepsy by allowing us to study the corresponding changes in neurological tissue and other variations underlying the mechanism of epilepsy. ${ }^{25}$ There are a variety of models for studying epilepsy, and the specific model used depends on the question being addressed by the researcher. Because of the limitations in studying epilepsy in human subjects, good animal models are necessary for uncovering the underlying pathology of the disease. ${ }^{25}$ Welldefined preclinical chemical, electrical stimulation, genetic, developmental, and trauma models for epilepsy research have been documented. ${ }^{25}$

\section{Epilepsy as a neuropsychiatric disorder}

Because of its neurological basis and associated psychopathological, cognitive, and linguistic problems, one can just as easily characterize epilepsy as a neuropsychiatric disorder. ${ }^{4}$ What is the use in defining epilepsy in this way? Enumerating the vast array of historical, cognitive, behavioral, psychological, and social issues surrounding epilepsy will allow us a more accurate understanding of these individuals, and can thus potentiate our therapeutic strategies for epilepsy by identifying unmet clinical needs. Widening our scope beyond the biological basis of disease allows us to take into account the obstacles faced by epileptics, which gives an opportunity to improve treatment and provide better quality of life. Studying the behavioral and cognitive abnormalities that parallel the underlying pathology gives us greater insight into the inner workings of the human mind. 


\section{Epilepsy in history and literature}

Epilepsy was described as early as 2000 BCE in Babylonian texts. ${ }^{18,26,27}$ The word "epilepsy" is derived from the Greek word "epilambanein", which is loosely translated as "to seize or take hold of". ${ }^{17,18,26-29}$ Popular belief at this time held that seizures were of supernatural origin, induced by the Gods. ${ }^{17,18}$ It is interesting to note, however, that as early as $\sim 400$ BCE, Hippocrates had branded epilepsy as a disease of the body and had denied that seizures were divinely provoked. ${ }^{17,18,26,27}$ Galen of Pergamon further characterized epilepsy ( 130-200 AD) and went so far as to say that seizures were a phenomenon of overactivation or irritation of the brain. ${ }^{17,18,27}$ Despite this portrayal of epilepsy as a quantifiable, observable defect in the bodies of those afflicted, the view that epilepsy has supernatural origin has persisted and is even depicted in films today. ${ }^{30}$ These beliefs have led to stigmatization and fear of epileptics, and a social environment in which epileptics feel outcast. ${ }^{26}$

Historically, there have been many implications and allusions toward epilepsy. Prominent historical figures such as Joan of Arc may have had seizures. ${ }^{18,31}$ According to scholars, Joan of Arc's supposed epileptiform seizures gave her divine purpose and the strength to lead France in an effort to free them from English dominion..$^{31}$ Though her actual participation in battle is questionable, her role in recovering France from the English dominion in the Lancastrian phase of the 100-year war is undeniable, as many of the noblemen leading troops apparently listened to her advice, believing it to be of divine origin. ${ }^{32}$ In "La Divina Comedia", Dante Alighieri quite accurately describes the paroxysmal change in behavior typical of an epileptic, and the postictal confusion that often immediately follows a seizure, in his depiction of a thief's punishment in the seventh circle of hell. ${ }^{18,33}$ Though it is unclear if Dante is aware of epilepsy as a medical disorder, the thief Vanni Fucci's seizure-like episode is precipitated by the bite of a serpent, perpetuating the supernatural explanation of epilepsy. ${ }^{33}$

\section{Epilepsy and criminality}

The stigmatization of epilepsy through religious texts and literature may have pervaded the early medical literature. Some people like Cesare Lombroso thought that epilepsy was clearly linked with criminality, in that people with epilepsy were much more likely to participate in criminal acts when compared to people without epilepsy. ${ }^{34}$ As late as the 1980s, the feasibility of an epileptic performing a complex aggressive act during an ictal state was studied, as the "epilepsy defense" was being used as a plea to insanity for some people who had committed violent crimes. ${ }^{35}$ More recent studies have found no such correlation between epilepsy and criminality. Though a link between aggression and the postictal state was shown in a preclinical murine model, there is no evidence to show that epileptics are prone to criminal behavior when compared to individuals without epilepsy. ${ }^{14,17}$ Poor understanding of a disorder and stigmatization can lead to bias, which may explain why Lombroso was convinced of the link between epilepsy and criminality.

\section{Epilepsy and psychology}

Though overarching links between a disorder like epilepsy and a social construct like criminality may not be present, there is a high comorbidity between epilepsy and psychiatric, behavioral disorders and impairments in social cognition. ${ }^{36-39}$ Studies that look at the link between epilepsy and psychiatric disorders have shown a correlation between peri-ictal and interictal psychiatric symptoms, stating that people who display psychiatric disturbances due to the seizure can develop or display the same symptoms between seizures. ${ }^{17}$ Mood and memory are two common deficits in epileptics, with many of these individuals reporting depressed mood and diminished memory capacity. ${ }^{14,17,18}$ Psychological disorders such as obsessive compulsive disorder, depression, and bipolar disorder have also been correlated with epilepsy. ${ }^{14}$

Sleep disturbances are also common, both due to nocturnal seizures and AEDs, and are the target of some holistic approaches to treatment of epilepsy. ${ }^{4,14,17,18,26-28,33,40}$ Since quality sleep has profound implications on our memory, mood, and cognitive functioning, one can conclude that impaired sleep due to epilepsy would negatively affect memory and cognitive functioning. ${ }^{40}$ Furthermore, sleep deprivation has been known to selectively impair the consolidation of positive and neutral memories, while not significantly affecting consolidation of negative memories; this could explain the negative mood experienced by many with epilepsy. ${ }^{40}$

The developmental implications of epilepsy on the brain are well documented. ${ }^{17,41-43}$ Epilepsy can interfere with the normal development of neural networks in children, and thus, early diagnosis and treatment is suspected to have an impact on limiting comorbid psychological issues associated with neural network developmental impairment due to epilepsy. ${ }^{17,41-43}$ These developmental impairments may lead to the array of cognitive impairments seen in epileptics and represent an unmet clinical need in epilepsy patients. ${ }^{4,14}$ The effect of epilepsy on the aging mind is not well studied. ${ }^{17}$ 


\section{Epilepsy and art}

Studying art created by individuals with epilepsy gives us insight into the peri-ictal and interictal experiences and the psychological consequences of living with epilepsy. . $^{1417,18,44}$ Epileptics often describe feelings of loneliness and isolation from the mainstream society, and gaps in time due to their seizures. ${ }^{44}$ This knowledge allows us to better treat individuals with epilepsy. Though there is no correlation between epilepsy and enhanced creativity in music and poetry, the impaired creativity due to epilepsy or epilepsy treatment provides an opportunity to better understand human creativity as a function of intact and properly functioning cerebral circuitry. ${ }^{28,29,45}$ Impairment of the creative process in epileptics is thought to be a result of the impaired neural circuitry. ${ }^{28,45}$

\section{Epilepsy and neuropsychology}

Examining epilepsy under the lens of neuropsychology allows us to better understand the disease. This understanding allows us to tailor treatment to epileptic individuals, allowing them to strive for equanimity, blend in a milieu in which epilepsy is stigmatized and feared for its supposed supernatural origin, and thrive despite impairment. Studying the historical, cognitive, behavioral, psychological, and social issues surrounding epilepsy allows us to improve treatment for epileptics and provides profound insight into the human mind.

Epilepsy has been found to be comorbid with many different psychiatric disorders. ${ }^{29,46,47}$ It has also been demonstrated that patients with depression are more likely to develop epileptic seizures compared to the general population, indicating a bidirectional relationship between epilepsy and psychiatric disorders. ${ }^{48,49}$ Patients with epilepsy are more likely to have mood disorders, like depression, with prevalence rates from $25 \%$ to $30 \%$, followed by anxiety, attention disorders, psychotic, and personality disorders ${ }^{46,50-53}$ Patients also have a higher suicide ideation of $30 \%$ and a rate of $11.5 \%$, which is ten times more than that of the general population (1.5\%). ${ }^{52,53}$ Patients with epilepsy who also have psychiatric disorders exhibit different clinical characteristics and are classified as "atypical". The classification of the psychiatric episodes is determined by their onset of seizures. Symptoms are put into four distinct categories: preictal (up to 2 days before the seizure), ictal (during the seizure), interictal (independent of the seizure), and postictal (following the seizure within 5 days). ${ }^{46}$ These psychiatric episodes vary from patient to patient, and the severity depends on a multitude of factors. ${ }^{48}$
Due to the comorbidity of psychiatric disorders and epilepsy, it is important for clinicians to notice the signs of mood disorders in order to treat epileptic patients. Some of the key things to look for during a psychiatric exam are: anhedonia, irritability, low self-esteem, decreased concentration, suicidal ideation, lethargy, and fatigue. ${ }^{54}$ Anxiety disorders are the second most prevalent form of psychiatric disorder in epileptic patients. Many patients experience anxiety as part of the seizure or aura. ${ }^{55}$ Postictal anxiety episodes appear in $45 \%$ of patients with epilepsy and are typically associated with other mood-related disorders. ${ }^{56}$ Attention deficit hyperactivity disorder is found in $20 \%-30 \%$ of pediatric epileptic patients. This disorder tends to persist through childhood into adulthood. Pediatric epileptic patients typically present with the classic signs of attention deficit disorders: impulsivity, irritability, and poor tolerance to challenging scenarios. ${ }^{46,56}$ Patients with epilepsy can also exhibit psychotic disorders with variable symptoms. Epileptic patients present less severe signs of psychosis compared to nonepileptic patients, thus making diagnosis of a psychotic disorder accompanying epilepsy more difficult. ${ }^{57}$

Incorrect diagnosis and treatment of the psychiatric components of epilepsy impact not only the patient, but also the entire health care system. Delayed diagnosis leads to an increased burden on the individual patient, their family, and society. ${ }^{58,59}$ Research has demonstrated that psychiatric comorbidity has a negative impact on the efficacy of surgery and the pharmaceutical treatment for epilepsy. ${ }^{60,61}$

\section{Animal models and the biology of epilepsy}

The biological bases of epilepsy and psychiatric disorders need to be studied further. However, there are a few key similarities between the two types of disorders that highlight their connection. In animal epilepsy models, serotonin and norepinephrine have critical roles in the pathophysiology. The lack of these neurotransmitters has been shown to increase the severity of seizures. ${ }^{62-64}$ Conversely, an increase in these neurotransmitters, facilitated through reuptake inhibitors, has been correlated with a decrease in severity of seizures. ${ }^{62-64}$ Changes in neurotransmitter levels are thought to be similarly important in psychiatric disorders. Researchers have used positron emission tomography scans to examine serotonin receptor (5-HT1A) activity. Both epilepsy patients and mood disorder patients exhibited a decrease in 5-HT1A binding activity in the temporal lobes near the raphe nuclei. ${ }^{65-68}$ Additional research is still needed to understand the complex mechanisms behind epilepsy and psychiatric disorders. 


\section{Treatments: the old and the new Pharmacologic treatments of epilepsy}

Current treatments of epileptic seizures are primarily controlled by readily available AEDs. ${ }^{69}$ One or multiple AEDs are generally used to treat symptoms in the majority of the epilepsy patient population. ${ }^{70}$ AEDs use various mechanisms of action to treat the hallmark symptoms of epileptic seizures. The ultimate goal of drug treatment is to decrease the electrical activity of the brain. This inhibition of neuronal firing is accomplished by blocking sodium channels, calcium channels, and glutamate-mediated responses ${ }^{19}$ Other AEDs provide neuronal inhibition by promotion of GABAergic release or increased potassium channel conductivity. ${ }^{19}$ Unfortunately, a noteworthy proportion (nearly $30 \%$ ) of the epileptic patient population exhibits or develops pharmacoresistance to AEDs. ${ }^{69}$ Pharmacoresistance of current AEDs is thought to be multifactorial and due to a variety of genetic and nongenetic factors. ${ }^{71}$ Although the exact mechanisms of pharmacoresistance in AEDs is not fully understood, the $A B C B 1$ gene is thought to play a role..$^{71} \mathrm{P}$-glycoprotein, a key transporter involved in drug efflux, is thought to be encoded by the $A B C B 1$ gene. ${ }^{71}$ It is suggested that variability within the $A B C B 1$ gene may play a role in preventing AEDs from reaching their target, thus resulting in pharmacoresistance to AEDs in patients with polymorphisms of this gene. ${ }^{71}$ Also, recent studies have found that certain variants of apolipoprotein $\mathrm{E}$ are linked with susceptibility toward certain types of epilepsy and also play a role in the pharmacoresistance against AEDs. ${ }^{72}$ Although the development of new AEDs has been proven to cause fewer drug interactions and side effects, they still do not reduce the frequency of drug-resistant epilepsy. ${ }^{70}$ When polytherapy using multiple AEDs fails to reduce epileptic symptoms, alternative and surgical treatment options should be discussed following the diagnosis of drug-resistant epilepsy. ${ }^{73}$

\section{Surgical and alternative treatments of epilepsy}

Alternative treatment options for epilepsy include surgical resection of the epileptic brain area, ketogenic diet, and neurostimulation devices such as deep brain stimulators and vagus nerve stimulators. ${ }^{73}$ It is becoming common practice to provide neurosurgical consultation to drug-resistant epilepsy patients after failure of $\sim 2$ AED regimens.$^{20}$ Earlier surgical consultation results in overall increased quality of life and decreased medical cost for patients. ${ }^{20}$ The temporal lobe is the most common area affected by drug-resistant epilepsy and resection of this brain area has been proven to be an effective treatment method..$^{20}$ Effective temporal lobe resection results in seizure control with minimal neurological deficits by removing the mesial temporal structures while maximizing conservation of the neocortex. ${ }^{20}$ Deep brain stimulation has proven effective in significantly reducing the seizure frequency as well as intractable aggressive behavior that is sometimes associated with drug-resistant epilepsy. ${ }^{74}$ Other neuromodulation-based treatments of drug-resistant epilepsy include vagus nerve stimulation that aims to reduce seizure frequency. ${ }^{75}$ Unfortunately, vagus nerve stimulation generally does not provide complete suppression of seizures, but is still effective in reducing the seizure frequency and increasing the response to initial seizure activity. ${ }^{75}$ Other alternative treatment options for drug-resistant epilepsy include a ketogenic diet. Although the mechanism of action is not well understood, some studies demonstrate a reduction in seizures in patients who adhere to these dietary restrictions. ${ }^{76}$

\section{Treatments targeting neuropsychiatric symptoms of epilepsy}

Patients with epilepsy are particularly vulnerable to neuropsychiatric symptoms including anxiety and depression. ${ }^{77}$ Although seizure is the most recognized comorbidity of epilepsy, anxiety and depression are rarely addressed in the differential diagnosis despite being the most prevalent psychiatric comorbidities of epilepsy. ${ }^{78}$ Research on anxiety and depression in epilepsy patients lacks exact clarity and longitudinal perspective; however, these neuropsychiatric symptoms are thought to be derived from either psychosocial or neurological causes. ${ }^{79}$ Although disorders such as anxiety and depression are often neglected in epilepsy patients, studies have demonstrated the effectiveness of specific, single-item screening methods for these disorders. ${ }^{80}$

There are many traditional and nontraditional treatment options for these neuropsychiatric symptoms. Traditional treatments of these symptoms often include antidepressants, specifically selective serotonin reuptake inhibitors and serotonin-noradrenaline reuptake inhibitors. ${ }^{79}$ Studies have found that antidepressants reduce the frequency of seizure episodes; however, the association of antidepressants with the underlying disease itself is yet to be investigated. ${ }^{79}$ Conducting research on this association between antidepressants and epilepsy would be difficult in human clinical trials due to numerous factors such as prolonged follow-up and multifactorial assessment of outcomes. ${ }^{79}$

The use of nontraditional treatments for neuropsychiatric symptoms of epilepsy is steadily increasing. A randomized controlled trial found benefits of mindfulness-based therapy 
for patients with drug-resistant epilepsy ${ }^{81}$ Patients experienced better outcomes in quality of life, mood, and seizure frequency, when compared to social support alone. ${ }^{81}$ Another nontraditional treatment is cannabidiol-based treatments for drug-resistant epilepsy. There is preclinical evidence suggesting that cannabidiol has antiseizure effects and could potentially help mediate neuropsychiatric symptoms of epilepsy. ${ }^{82}$ Despite the legal challenges in this area of research, there seems to be growing support in advancing cannabidiol-based treatments. ${ }^{82}$

There is a lack of research on the association between epileptic drugs and the neuropsychiatric symptoms of the disease. It is difficult to assess the outcomes in animal models because both chronic epilepsy models and chronic antidepressant treatment are required to simulate the disease and treatment course in humans. ${ }^{79}$ Recent studies have shown that the pilocarpine model is an appropriate method to recreate the neurobehavioral disruptions seen in TLE in humans. ${ }^{83}$ Further investigations using the pilocarpine model with chronic antidepressant treatment may be able to replicate the disease course accurately in humans.

\section{Stem cell therapy and epilepsy Preclinical and clinical studies}

Therapeutic use of stem cells has been reported in multiple neurological disease models such as multiple sclerosis, stroke, and Parkinson's disease. ${ }^{22}$ Stem cell transplantation therapy has been increasingly explored as a potential treatment option in epilepsy. ${ }^{9}$ Preclinical and clinical studies of this approach have utilized several cell types including hippocampal precursor cells, neural stem cells (NSCs), GABAergic precursor cells, and systemic administration of bone marrow-derived mononuclear cells and mesenchymal cells. ${ }^{9}$ When NSCs were first injected into a pilocarpine rat model, it resulted in a significant decrease in spontaneous motor seizures. ${ }^{84}$ Although each cell type utilizes a different mechanism of action, they all strive to reduce seizure activity in the epileptic area of brain tissue.

Bilateral hippocampal precursor cell grafting has been shown to effectively decrease the frequency of seizures in animal models. ${ }^{85}$ This therapy strives to repair the disrupted circuitry within the epileptic area of the brain by reducing aberrant mossy fiber sprouting, while also activating the GABAergic interneurons. ${ }^{9}$ The increase of GABAergic interneurons translates into more inhibitory control, thereby providing the desired effects in the epileptic brain areas. ${ }^{85}$

NSC transplantation is thought to utilize a multifaceted approach by creating new GABAergic interneurons and also new astrocytes. ${ }^{9}$ The underlying significance of new astrocytes is the expression of glial-derived neurotrophic factor (GDNF) that has anticonvulsant properties. ${ }^{86}$ There are evident therapeutic effects of NSC transplantation, including reduction of seizure frequency and duration, despite no changes occurring in cognitive function. ${ }^{86}$ The loss of GABAergic neurons produces a lack of inhibitory control on the epileptic brain area. ${ }^{9}$ Thus, GABAergic cell therapy focuses on replacing the loss of GABAergic neurons, thus increasing the inhibitory synaptic control of the affected area. ${ }^{9}$ Studies have shown the anticonvulsant effects of directly grafting engineered GABA-producing cells. ${ }^{9}$ Unfortunately, many of these beneficial anticonvulsant effects have been shown to be temporary due to poor graft survival. ${ }^{9}$ Other studies have explored these effects when using the precursor cells derived from different areas such as the lateral ganglionic eminence and the medial ganglionic eminence (MGE). ${ }^{9}$ Embryonic progenitor cells from the lateral ganglionic eminence treated with fibroblast growth factor-2 and a caspase inhibitor have been found to provide lasting inhibition and reduction in the frequency of spontaneous recurrent seizures (SRS). ${ }^{9}$ In addition, MGE progenitor cell grafting has been explored due to the cells' characteristic ability to migrate to surrounding regions from the initial graft site. ${ }^{9}$ It is suggested that there is a connection between the pyramidal neurons and the newly formed interneurons which produces the inhibitory effect. ${ }^{87}$ Further investigation in clinical GABAergic cell therapy must explore the longterm effects of grafting, results in drug-resistant epilepsy, and usefulness in reducing the cognitive and mood impairments associated with epilepsy. ${ }^{9}$

\section{Autologous stem cell transplantation for epilepsy}

The debate continues on what type of transplantation, autologous or allogeneic, to use when treating diseases. These stem cells can be induced to differentiate into a specific type of specialized cells before the actual transplantation procedure. ${ }^{88,89}$ Both autologous and allogeneic transplantation have strengths and weaknesses related to efficacy and safety. In allogeneic transplantation, the donor is not the host, but a very close human leukocyte antigen (HLA) match, like the host's immediate family member. ${ }^{90}$ The necessity for a close HLA match creates problems with availability and compliance..$^{90}$ In autologous transplantation, the donor and the host are the same individual, thus ensuring an exact HLA match. These autologous cells can be differentiated into many cell types. ${ }^{89}$ The primary weaknesses of an autologous 
transplantation are the limited quantity of stem cells that can be extracted and the significant length of time required for proliferation. ${ }^{91}$ Autologous transplantation offers some advantages in regard to patient ethics, prognosis, and safety. Since autologous transplants originate from the same individual as the recipient, there is no need to use embryonic or fetal tissues, thereby bypassing some of the more controversial ethical concerns of stem cell transplantation. Autologous transplantation has a reduced risk of tumorigenesis and graft rejection, compared to allogeneic transplantation..$^{92-95}$ As a result, most allogeneic transplantation requires the administration of immunosuppressants to attenuate the immune response of the graft and of the host, as seen in graftversus-host disease (GVHD). Autologous transplantation does not have the risk for GVHD since the donor and host are the same. The prevalence of GVHD is increasing due to the rise in the number of transplantations. ${ }^{96}$

GVHD has three requirements: the graft should have immunologically competent cells, the host and donor antigens must be different, and the host must be incapable of attacking the transplanted cells. ${ }^{97}$ The mechanism of action is described as a response from the $\mathrm{T}$ cells that are in the graft against the host tissue. ${ }^{97}$ This immune response leads to multiple organ system damage and possible rejection of the graft. ${ }^{90}$ A systematic review found that autologous transplantation did not increase the risk of mortality or the incidence of tumorigenesis. ${ }^{98}$ Studies have also found that autologous transplants from older patients are less likely to cause tumors. ${ }^{93,99}$ The reduced risks associated with autologous transplantation make it a prime candidate for expedited review by the US Food and Drug Administration which is intended to evaluate a novel therapy that satisfies an unmet medical need for a serious, debilitating medical condition. In this case, autologous stem cell transplantation offers certain advantages over current treatments for epilepsy, and thus would be well suited for expedited review. ${ }^{100}$ There are clinical trials in Phase I/II for autologous transplantation of NSCs for Parkinson's disease. ${ }^{101}$ Epilepsy is the next neurological disorder that can be treated with stem cell therapy. Stem cells from the subventricular zone (SVZ) and other areas along the dentate gyrus can be isolated at present. ${ }^{102}$ These cells can be isolated by a temporal lobectomy or endoscopic resection. ${ }^{103,104}$

Autologous transplantation of NSC has emerged as an area of interest due to the observed neurogenesis in the hippocampus and the parahippocampal gyrus which are involved in TLE. ${ }^{105,106}$ The intended purposes of stem cell transplantation are to provide growth factors and trophic factors, while facilitating neurogenesis with a special focus on differentiation into the inhibitory GABAergic neurons whose loss has been implicated in epilepsy. ${ }^{107}$ The ability of NSCs to differentiate into GABAergic interneurons has been observed in the dentate gyrus of mice with TLE. ${ }^{108}$ The NSCs used in transplantation can be obtained from the SVZ, which is one area of persistent NSC presence, and then expanded in culture before transplantation. Other sources of NSCs include the embryonic MGE ${ }^{86}$ Neurogenesis presents an issue of trade-off in the TLE model. Neurogenesis in the acute phase after insult is abnormal and deleterious, whereas neurogenesis in the chronic phase is critical to counteract the neurodegeneration that is associated with epilepsy. ${ }^{109,110}$ High temporal specificity is, therefore, as important an element as spatial specificity in any future epilepsy therapy based on stem cells.

Induced pluripotent stem cells (iPSCs) are stem cells derived from adult cells that may offer the advantages of autologous transplantation. The groundbreaking induction of somatic cells into pluripotent stem cells was first achieved in 2006 by Takahashi and Yamanaka by introducing certain reprogramming genes found to drive stem cell self-renewal, such as Oct-4 and SOX2, into fibroblasts. ${ }^{111}$ The ability to generate iPSCs provides the promise of autologous cell replacement and gene therapy to reprogram cells. Viral vectors to deliver the reprogrammed transgenes may involve the use of permanently integrating viruses. ${ }^{111,112}$ Whereas genetic stability is achieved with permanently introducing transgenes, alternative approaches employing nonintegrating viruses such as adenoviruses and Epstein-Barr virus have been explored. ${ }^{112}$ Another use of iPSCs is generation of a population of neural cells that release specific neurotransmitters (eg, GABA) and integrate them into a specific location such as the dentate gyrus. ${ }^{113}$ Such targeted introduction of neurotransmitter-producing neural cells could be a powerful autologous therapy for epilepsy in the future. In parallel, iPSCs may serve as a research tool to generate patient-derived neural cells for mechanistic studies and drug testing, ${ }^{114,115}$ which will facilitate human modeling of epilepsy allowing a better understanding of the disease and its treatment.

Our TLE model uses intraventricular injection of kainic acid (KA) to induce SRS in virtually all rats within 3-4 months, while other groups use pilocarpine. ${ }^{116} \mathrm{KA}$ was used to create a unilateral hippocampal injury model of TLE through the loss of CA1 and CA3 pyramidal neurons, similar to the hippocampal sclerosis seen in TLE. ${ }^{117}$ NSCs obtained from the adult SVZ were implanted into the hippocampus of rats that were receiving KA. A statistically significant 
decrease in abnormal electroencephalography spiking was observed 2 weeks after NSC transplantation. ${ }^{118}$ At 5 weeks posttransplantation, grafts of NSCs were detected at CA3 of the hippocampus and in the subgranular zone into which they had migrated. Most of the transplanted NSCs were found to express glial fibrillary acidic protein, indicating that they were astrocytes, but some NSCs also expressed neuronal nuclei $(\mathrm{NeuN})$, indicating that they had differentiated into mature neurons. The transplantation of MGE-derived NSCs saw a $43 \%$ decrease in the frequency of SRS at 3 months postgrafting. NSC-derived cells were found in the CA3 and CA1 fields of the hippocampus with an approximate yield of $28 \%$ of the injected cells. ${ }^{86}$ Transplanted NSCs have been observed to have a survival rate of nearly $30 \%$ at 3 months after grafting, with $\sim 91 \%$ of those surviving NSCs differentiating into GABAergic neurons. ${ }^{119}$ The differentiated GABAergic interneurons were found to express markers such as neuropeptide $\mathrm{Y}$, which has been shown to inhibit glutamatergic excitation in the epileptic dentate gyrus. ${ }^{120}$ NSCs have also demonstrated secretion of stem cell factor with concomitant increase in c-Kit, the ligand for stem cell factor. ${ }^{121}$ Such stem cell factors likely constitute the mechanisms for the observed reduction in epileptic activity after transplantation of NSCs.

Immunohistochemical staining revealed increased preservation of GABAergic inhibitory neurons and a reduction in abnormal mossy fiber growth, which has been correlated with the increased excitability of the hippocampus in epilepsy. ${ }^{116,122}$ Our laboratory has also reported that infusion of erythropoietin significantly increased the survival of transplanted NSCs while suppressing aberrant neurogenesis in the dentate gyrus. ${ }^{118,123}$ The results of decreased abnormal neuronal activity, increased secretion of neurotrophic factors, and decreased abnormal mossy fiber growth suggest a neuroprotective effect against seizures from the transplanted NSCs. Grafts of NSCs have also been observed to increase the numbers of GABAergic neurons and GDNF-secreting cells in the hippocampus. ${ }^{86}$ GDNF levels were increased in the hippocampus after seizures induced by KA and the levels correlated with anticonvulsant effects. ${ }^{124,125}$

Transplantation of NSCs in the pilocarpine-induced TLE model has demonstrated similar effects as in the KA-induced model. The transplantation of $\beta$-galactosidase-encoded human NSCs in rats exhibiting SRS due to administration of pilocarpine saw only $13 \%$ of the rats receiving NSCs to continue exhibiting SRS. ${ }^{22} \beta$-gal+ NSCs were found in the hippocampal CA1 and CA3 areas among others, while only a fraction of them were found to be mature NeuN-expressing mature neurons. Some of the $\beta$-gal+ cells demonstrated some degree of differentiation into GABAergic neurons by expressing identifying markers.

\section{Stem cell therapy for treatment of epilepsy-induced neuropsychiatric symptoms}

Stem cell therapy presents an intriguing alternative approach to treat epilepsy that is fundamentally different from anticonvulsants and electrical stimulation which seek to manage the symptoms and not address the underlying causes of epilepsy. Stem cell therapy has the potential to provide neurotrophic factors and stimulate neurogenesis. While NSC grafts have demonstrated a reduction in SRS, further studies are needed to assess the differentiation of stem cells into GABAergic interneurons and other cell types. Establishment of a consistent method of controlled differentiation of stem cells into desired cells could allow for epilepsy to be treated with the replacement of deficient or defective neurons using the patient's own stem cells. At the same time, the ability of the transplanted stem cells to differentiate must be balanced with the danger of tumorigenesis. Uncontrolled differentiation and migration of stem cells could pose a grave risk for tumor growth and metastasis. Further research into the longevity of stem cells along with their long-term production of trophic factors would help evaluate the safety and efficacy of stem cell therapy toward treating epilepsy, which is most often a lifelong neurological disease.

There have been various studies that investigated the administration of stem cells into rat and mouse models of status epilepticus and other relevant animal models of epilepsy that provide valuable insights into the clinical benefits of stem cells as a potential treatment option for those suffering with epilepsy. The administration of stem cells into the status epilepticus animals has been shown to ameliorate many pathological symptoms of the disease, attributed to neuroprotection. Stem cell transplanted epileptic animals display reduced seizures (both in frequency and duration), and improved memory and learning, with postulated neuroprotective effects characterized by decreased neuronal loss, increased neurogenesis, reduced microglia and astrocyte

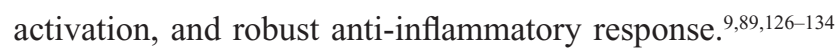
Although these studies investigated the hallmark biological basis of the disease, the psychiatric component of epilepsy was not examined. To date, no definitive study has explored the effects of stem cells on psychiatric symptoms in animal models of epilepsy. 
Currently, neuropsychiatric disorders are considered a comorbidity of epilepsy. The use of stem cell transplantation in treating epilepsy-induced neuropsychiatric symptoms still requires further investigation to determine its safety and efficacy. It is currently hypothesized that neurogenesis in mood-affecting areas of the brain will improve depression and other neuropsychiatric disorders. ${ }^{23}$ Despite the presence of optimistic theories on the effectiveness of stem cell transplantation, careful and rigorous preclinical studies are warranted to advance cell therapy for treating the neurologic and neuropsychiatric symptoms of epilepsy.

\section{Recapping the future of epilepsy}

Epilepsy is a debilitating disease that affects millions of people and is currently only managed and not cured. The use of AEDs and surgical resection are treatments that forgo the neuropsychiatric aspect of epilepsy, a component that is just as important as the neurological aspect. Autologous stem cell therapy is a treatment option that is gaining ground for treating neurological and psychiatric disorders. This cell-based therapy can be used for the treatment of epilepsy. Autologous stem cells reduce the risk of GVHD and can be harvested from the SVZ during surgical resection. In epileptic patients, these cells can be primed to reconstruct the dysfunctional neural circuitry, although not correcting the GABA deficiency. As in any novel treatment, caution in translating laboratory investigations into clinical applications will require careful and rigorous preclinical studies on the safety and efficacy of the therapies. Optimization of stem cell dose, route of cell delivery, and timing of intervention need to be tested in clinically relevant models of epilepsy that capture both neurologic and neuropsychiatric symptoms of the disease.

\section{Disclosure}

The authors report no conflicts of interest in this work.

\section{References}

1. Hauser WA, Kurland LT. The epidemiology of epilepsy in Rochester, Minnesota, 1935 through 1967. Epilepsia. 1975;16(1):1-66.

2. Fisher RS, van Emde Boas W, Blume W, et al. Epileptic seizures and epilepsy: definitions proposed by the International League Against Epilepsy (ILAE) and the International Bureau for Epilepsy (IBE). Epilepsia. 2005;46(4):470-472.

3. Fisher RS, Acevedo C, Arzimanoglou A, et al. ILAE Official Report: A practical clinical definition of epilepsy. Epilepsia. 2014;55(4):475-482. doi:10.1111/epi.12550.

4. Plioplys S, Dunn DW, Caplan R. 10-year research update review: psychiatric problems in children with epilepsy. $J$ Am Acad Child Adolesc Psychiatry. 2007;46(11):1389-1402.

5. Shinnar S, O'Dell C, Berg AT. Distribution of epilepsy syndromes in a cohort of children prospectively monitored from the time of their first unprovoked seizure. Epilepsia. 1999;40(10):1378-1383.
6. Shinnar S, Pellock JM. Update on the epidemiology and prognosis of pediatric epilepsy. J Child Neurol. 2002;17(Suppl 1):S4-S17.

7. Jobst BC, Cascino GD. Resective epilepsy surgery for drug-resistant focal epilepsy: a review. JAMA. 2015;313(3):285-293.

8. Comorbidity in Adults with Epilepsy - United States, 2010. Availlable from: http://www.cdc.gov/mmwr/preview/mmwrhtml/mm6243a2.htm. Accessed March 8, 2016.

9. Shetty AK, Upadhya D. GABA-ergic cell therapy for epilepsy: Advances, limitations and challenges. Neurosci Biobehav Rev. 2016;62:35-47.

10. Devinsky O. Diagnosis and treatment of temporal lobe epilepsy. Rev Neurol Dis. 2004;1(1):2-9.

11. Lewis DV. Losing neurons: selective vulnerability and mesial temporal sclerosis. Epilepsia. 2005;46(Suppl 7):39-44.

12. Berg AT, Berkovic SF, Brodie MJ, et al. Revised terminology and concepts for organization of seizures and epilepsies: report of the ILAE commission on classification and terminology, 2005-2009. Epilepsia. 2010;51(4):676-685.

13. Miyoshi K, Morimura Y, Maeda K, editors. Neuropsychiatric Disorders. Tokyo: Springer Japan; 2010. Available from: http://link.springer. com/10.1007/978-4-431-53871-4. Accessed March 6, 2016.

14. Rektor I, Schachter SC, Arya R, et al. Third International Congress on epilepsy, brain, and mind: Part 2. Epilepsy Behav. 2015;50:138-159.

15. Verrotti A, Carrozzino D, Milioni M, Minna M, Fulcheri M. Epilepsy and its main psychiatric comorbidities in adults and children. J Neurol Sci. 2014;343(1-2):23-29.

16. Kanner AM. Management of psychiatric and neurological comorbidities in epilepsy. Nat Rev Neurol. 2016;12(2):106-116.

17. Rektor I, Schachter SC, Arzy S, et al. Epilepsy, behavior, and art (Epilepsy, Brain, and Mind, part 1). Epilepsy Behav. 2013;28(2):261-282.

18. Korczyn AD, Schachter SC, Amlerova J, et al. Third International Congress on epilepsy, brain and mind: Part 1. Epilepsy Behav. 2015; 50:116-137.

19. Stafstrom CE, Carmant L. Seizures and epilepsy: an overview for neuroscientists. Cold Spring Harb Perspect Med. 2015;5(6).pii: a002426.

20. Ramey WL, Martirosyan NL, Lieu CM, Hasham HA, Lemole GM, Weinand ME. Current management and surgical outcomes of medically intractable epilepsy. Clin Neurol Neurosurg. 2013;115(12): 2411-2418.

21. Williams NR, Okun MS. Deep brain stimulation (DBS) at the interface of neurology and psychiatry. J Clin Invest. 2013;123(11):4546-4556.

22. Chu K, Kim M, Jung KH, et al. Human neural stem cell transplantation reduces spontaneous recurrent seizures following pilocarpine-induced status epilepticus in adult rats. Brain Res. 2004;1023(2):213-221.

23. Valenzuela M, Sidhu K, Dean S, Sachdev P. Neural stem cell therapy for neuropsychiatric disorders. Acta Neuropsychiatr. 2007;19(1): $11-26$.

24. Braun SMG, Jessberger S. Adult neurogenesis and its role in neuropsychiatric disease, brain repair and normal brain function. Neuropathol Appl Neurobiol. 2014;40(1):3-12.

25. Raol YH, Brooks-Kayal AR. Experimental models of seizures and epilepsies. Prog Mol Biol Transl Sci. 2012;105:57-82.

26. Ladino LD, Rizvi S, Téllez-Zenteno JF. Epilepsy through the ages: an artistic point of view. Epilepsy Behav. 2016;57(Pt B):255-264.

27. Magiorkinis E, Sidiropoulou K, Diamantis A. Hallmarks in the history of epilepsy: epilepsy in antiquity. Epilepsy Behav. 2010;17(1):103-108.

28. Mula M, Hermann B, Trimble MR. Neuropsychiatry of creativity. Epilepsy Behav. 2016;57(Pt B):225-229.

29. Hesdorffer DC, Trimble M. Musical and poetic creativity and epilepsy. Epilepsy Behav. 2016;57(Pt B):234-347.

30. Baxendale S. Epilepsy on the silver screen in the 21 st century. Epilepsy Behav. 2016;57(Pt B):270-247.

31. Nicastro N, Picard F. Joan of Arc: Sanctity, witchcraft or epilepsy? Epilepsy Behav. 2016;57(Pt B):247-250.

32. Pernoud R. Joan of Arc by Herself and Her Witnesses. New York: Stein and Day; 1966.

33. Mula M. Epilepsy in Dante's poetry. Epilepsy Behav. 2016;57(Pt B): 251-254. 
34. Monaco F, Mula M. Cesare Lombroso and epilepsy 100 years later: an unabridged report of his original transactions. Epilepsia. 2011;52(4): 679-688.

35. Delgado-Escueta AV, Mattson RH, King L, et al. Special report. The nature of aggression during epileptic seizures. $N$ Engl J Med. 1981;305(12):711-716.

36. Realmuto S, Zummo L, Cerami C, et al. Social cognition dysfunctions in patients with epilepsy: Evidence from patients with temporal lobe and idiopathic generalized epilepsies. Epilepsy Behav. 2015;47:98-103.

37. Mula M, Hesdorffer DC. Suicidal behavior and antiepileptic drugs in epilepsy: analysis of the emerging evidence. Drug Healthc Patient Saf. 2011;3:15-20

38. Hecimovic H, Santos JM, Carter J, et al. Depression but not seizure factors or quality of life predicts suicidality in epilepsy. Epilepsy Behav. 2012;24(4):426-429.

39. Kanner AM. Mood disorder and epilepsy: a neurobiologic perspective of their relationship. Dialogues Clin Neurosci. 2008;10(1):39-45.

40. Walker MP, Stickgold R. Sleep, memory, and plasticity. Annu Rev Psychol. 2006;57:139-166.

41. Bullmore E, Sporns O. The economy of brain network organization. Nat Rev Neurosci. 2012;13(5):336-349.

42. Kramer MA, Cash SS. Epilepsy as a disorder of cortical network organization. Neuroscientict. 2012;18(4):360-372.

43. Jensen FE. Epilepsy as a spectrum disorder: Implications from novel clinical and basic neuroscience. Epilepsia. 2011;52(Suppl 1):1-6.

44. Schachter SC. Epilepsy and art: Windows into complexity and comorbidities. Epilepsy Behav. 2016;57(Pt B):265-269.

45. Zubkov S, Friedman D. Epilepsy treatment and creativity. Epilepsy Behav. 2016;57(Pt B):230-233.

46. García-Morales I, de la Peña Mayor P, Kanner AM. Psychiatric comorbidities in epilepsy: identification and treatment. Neurologist. 2008; 14(6 Suppl 1):S15-S25.

47. Kanner AM, Balabanov A. Depression and epilepsy: how closely related are they? Neurology. 2002;58(8 Suppl 5):S27-S39.

48. Kanner AM. Depression and epilepsy: a new perspective on two closely related disorders. Epilepsy Curr. 2006;6(5):141-146.

49. Hesdorffer DC, Hauser WA, Olafsson E, Ludvigsson P, Kjartansson O. Depression and suicide attempt as risk factors for incident unprovoked seizures. Ann Neurol. 2006;59(1):35-41.

50. Swinkels WA, Kuyk J, van Dyck R, Spinhoven P. Psychiatric comorbidity in epilepsy. Epilepsy Behav. 2005;7(1):37-50.

51. Kogeorgos J, Fonagy P, Scott DF. Psychiatric symptom patterns of chronic epileptics attending a neurological clinic: a controlled investigation. Br J Psychiatry. 1982;140:236-243.

52. Hermann BP, Seidenberg M, Bell B. Psychiatric comorbidity in chronic epilepsy: identification, consequences, and treatment of major depression. Epilepsia. 2000;41(Supp1 2):S31-S41.

53. Lambert MV, Robertson MM. Depression in epilepsy: etiology, phenomenology, and treatment. Epilepsia. 1999;40(Suppl 10):S21-S47.

54. Cramer JA, Blum D, Reed M, Fanning K; Epilepsy Impact Project Group. The influence of comorbid depression on seizure severity. Epilepsia. 2003;44(12):1578-1584.

55. Marcangelo MJ, Ovsiew F. Psychiatric aspects of epilepsy. Psychiatr Clin North Am. 2007;30(4):781-802.

56. Jones JE, Hermann BP, Woodard JL, et al. Screening for major depression in epilepsy with common self-report depression inventories. Epilepsia. 2005;46(5):731-735.

57. Tadokoro Y, Oshima T, Kanemoto K. Interictal psychoses in comparison with schizophrenia - a prospective study. Epilepsia. 2007;48(12): 2345-2351.

58. Lee WC, Arcona S, Thomas SK, Wang Q, Hoffmann MS, Pashos CL. Effect of comorbidities on medical care use and cost among refractory patients with partial seizure disorder. Epilepsy Behav. 2005;7(1):123-126.

59. Sancho J, Peña P, Rufo M, Palacios G, Masramon X, Rejas J; LINCE Study Collaborative Group. Health and non-health care resources use in the management of adult outpatients with drug-resistant epilepsy in Spain: a cost-of-illness study (LINCE study). Epilepsy Res. 2008;81(2-3):176-187.
60. Anhoury S, Brown RJ, Krishnamoorthy ES, Trimble MR. Psychiatric outcome after temporal lobectomy: a predictive study. Epilepsia. 2000;41(12):1608-1615.

61. Hitiris N, Mohanraj R, Norrie J, Sills GJ, Brodie MJ. Predictors of pharmacoresistant epilepsy. Epilepsy Res. 2007;75(2-3):192-196.

62. Jobe PC, Dailey JW, Wernicke JF. A noradrenergic and serotonergic hypothesis of the linkage between epilepsy and affective disorders. Crit Rev Neurobiol. 1999;13(4):317-356.

63. Dailey JW, Mishra PK, Ko KH, Penny JE, Jobe PC. Serotonergic abnormalities in the central nervous system of seizure-naive genetically epilepsy-prone rats. Life Sci. 1992;50(4):319-326.

64. Ryu JR, Jobe PC, Milbrandt JC, et al. Morphological deficits in noradrenergic neurons in GEPR-9s stem from abnormalities in both the locus coeruleus and its target tissues. Exp Neurol. 1999;156(1):84-91.

65. Cheetham SC, Crompton MR, Czudek C, Horton RW, Katona CL, Reynolds GP. Serotonin concentrations and turnover in brains of depressed suicides. Brain Res. 1989;502(2):332-340.

66. Giovacchini G, Toczek MT, Bonwetsch R, et al. 5-HT 1A receptors are reduced in temporal lobe epilepsy after partial-volume correction. J Nucl Med. 2005;46(7):1128-1135.

67. Savic I, Lindström P, Gulyás B, Halldin C, Andrée B, Farde L. Limbic reductions of 5-HT1A receptor binding in human temporal lobe epilepsy. Neurology. 2004;62(8):1343-1351.

68. Toczek MT, Carson RE, Lang L, et al. PET imaging of 5-HT receptor binding in patients with temporal lobe epilepsy. Neurology. 2003;60(5):749-756.

69. Remy S, Beck H. Molecular and cellular mechanisms of pharmacoresistance in epilepsy. Brain. 2006;129(Pt 1):18-35.

70. Schmidt D, Schachter SC. Drug treatment of epilepsy in adults. BMJ. 2014;348:g254.

71. Keangpraphun T, Towanabut S, Chinvarun Y, Kijsanayotin P. Association of ABCB1 C3435T polymorphism with phenobarbital resistance in Thai patients with epilepsy. J Clin Pharm Ther. 2015;40(3): 315-319.

72. Gong J-E, Qu J, Long H-Y, et al. Common variants of APOE are associated with anti-epileptic drugs resistance in Han Chinese patients. Int $J$ Neurosci. Epub 2016 Feb 2.

73. López González FJ, Rodríguez Osorio X, Gil-Nagel Rein A, et al. Drugresistant epilepsy: definition and treatment alternatives. Neurologia. 2015;30(7):439-446.

74. Benedetti-Isaac JC, Torres-Zambrano M, Vargas-Toscano A, et al. Seizure frequency reduction after posteromedial hypothalamus deep brain stimulation in drug-resistant epilepsy associated with intractable aggressive behavior. Epilepsia. 2015;56(7):1152-1161.

75. Englot DJ, Rolston JD, Wright CW, Hassnain KH, Chang EF. Rates and predictors of seizure freedom with vagus nerve stimulation for intractable epilepsy. Neurosurgery. 2016;79(3):345-353.

76. Zamani GR, Mohammadi M, Ashrafi MR, et al. The effects of classic ketogenic diet on serum lipid profile in children with refractory seizures. Acta Neurol Belg. 2016. [Epub ahead of print]

77. Hamilton KT, Anderson CT, Dahodwala N, et al. Utilization of care among drug resistant epilepsy patients with symptoms of anxiety and depression. Seizure. 2014;23(3):196-200.

78. Selassie AW, Wilson DA, Martz GU, Smith GG, Wagner JL, Wannamaker BB. Epilepsy beyond seizure: a population-based study of comorbidities. Epilepsy Res. 2014;108(2):305-315.

79. Cardamone L, Salzberg MR, O'Brien TJ, Jones NC. Antidepressant therapy in epilepsy: can treating the comorbidities affect the underlying disorder? Br J Pharmacol. 2013;168(7):1531-1554.

80. Carrozzino D, Marchetti D, Laino D, et al. Anxiety in adolescent epilepsy. A clinimetric analysis. Nord J Psychiatry. 2016;70(6):424-429.

81. Tang V, Poon WS, Kwan P. Mindfulness-based therapy for drugresistant epilepsy: An assessor-blinded randomized trial. Neurology. 2015;85(13):1100-1107.

82. Devinsky O, Cilio MR, Cross H, et al. Cannabidiol: pharmacology and potential therapeutic role in epilepsy and other neuropsychiatric disorders. Epilepsia. 2014;55(6):791-802. 
83. Lopes MW, Lopes SC, Santos DB, et al. Time course evaluation of behavioral impairments in the pilocarpine model of epilepsy. Epilepsy Behav. 2016;55:92-100.

84. Roper SN, Steindler DA. Stem cells as a potential therapy for epilepsy. Exp Neurol. 2013;244:59-66.

85. Hattiangady B, Rao MS, Shetty AK. Grafting of striatal precursor cells into hippocampus shortly after status epilepticus restrains chronic temporal lobe epilepsy. Exp Neurol. 2008;212(2):468-481.

86. Waldau B, Hattiangady B, Kuruba R, Shetty AK. Medial Ganglionic Eminence-derived Neural Stem Cell Grafts Ease Spontaneous Seizures and Restore GDNF Expression in a Rat Model of Chronic Temporal Lobe Epilepsy. Stem Cells. 2010;28(7):1153-1164.

87. Jaiswal MK, Keros S, Zhao M, et al. Reduction in focal ictal activity following transplantation of MGE interneurons requires expression of the GABAA receptor $\alpha 4$ subunit. Front Cell Neurosci. 2015;9:127.

88. Agadi S, Shetty AK. Concise review: prospects of bone marrow mononuclear cells and mesenchymal stem cells for treating status epilepticus and chronic epilepsy. Stem Cells. 2015;33(7):2093-2103.

89. Huicong K, Zheng X, Furong W, et al. The imbalanced expression of adenosine receptors in an epilepsy model corrected using targeted mesenchymal stem cell transplantation. Mol Neurobiol. 2013;48(3):921-930.

90. Duncombe A. ABC of clinical haematology. Bone marrow and stem cell transplantation. BMJ. 1997;314(7088):1179-1182.

91. Berner A, Reichert JC, Woodruff MA, et al. Autologous vs allogenic mesenchymal progenitor cells for the reconstruction of critical sized segmental tibial bone defects in aged sheep. Acta Biomater. 2013;9(8): 7874-7884.

92. de Munter JP, Wolters EC. Autologous stem cells in neurology: is there a future? J Neural Transm (Vienna). 2012;120(1):65-73.

93. Sanberg PR, Eve DJ, Metcalf C, Borlongan CV. Chapter 7 Advantages and challenges of alternative sources of adult-derived stem cells for brain repair in stroke. In: Dunnett SB and Björklund A, editors. Progress in Brain Research. Vol 201. Functional Neural Transplantation III: Primary and Stem Cell Therapies for Brain Repair, Part II. Amsterdam, Netherlands: Elsevier; 2012:99-117. Available from: http://www.sciencedirect.com/science/article/pii/ B9780444595447000068. Accessed March 3, 2016.

94. Erlandsson A, Lin CH, Yu F, Morshead CM. Immunosuppression promotes endogenous neural stem and progenitor cell migration and tissue regeneration after ischemic injury. Exp Neurol. 2011;230(1): 48-57.

95. Yoon SH, Shim YS, Park YH, et al. Complete spinal cord injury treatment using autologous bone marrow cell transplantation and bone marrow stimulation with granulocyte macrophage-colony stimulating factor: Phase I/II clinical trial. Stem Cells. 2007;25(8):2066-2073.

96. Flowers ME, Martin PJ. How we treat chronic graft-versus-host disease. Blood. 2015;125(4):606-615.

97. Ferrara JLM, Levine JE, Reddy P, Holler E. Graft-versus-Host Disease. Lancet. 2009;373(9674):1550-1561.

98. Benoit E, O'Donnell TF, Patel AN. Safety and efficacy of autologous cell therapy in critical limb ischemia: a systematic review. Cell Transplant. 2013;22(3):545-562.

99. Strauer BE, Steinhoff G. 10 years of intracoronary and intramyocardial bone marrow stem cell therapy of the heart: from the methodological origin to clinical practice. J Am Coll Cardiol. 2011;58(11): 1095-1104.

100. Commissioner O of the. Fast Track, Breakthrough Therapy, Accelerated Approval, Priority Review. Available from: http://www.fda.gov/ ForPatients/Approvals/Fast/default.htm. Accessed March 3, 2016.

101. Trounson A, Thakar RG, Lomax G, Gibbons D. Clinical trials for stem cell therapies. BMC Med. 2011;9:52.

102. Andres RH, Choi R, Steinberg GK, Guzman R. Potential of adult neural stem cells in stroke therapy. Regen Med. 2008;3(6): 893-905.

103. Westerlund U, Svensson M, Moe MC, et al. Endoscopically harvested stem cells: a putative method in future autotransplantation. Neurosurgery. 2005;57(4):779-784.
104. Ayuso-Sacido A, Roy NS, Schwartz TH, Greenfield JP, Boockvar JA. Long-term expansion of adult human brain subventricular zone precursors. Neurosurgery. 2008;62(1):223-231.

105. Eriksson PS, Perfilieva E, Björk-Eriksson T, et al. Neurogenesis in the adult human hippocampus. Nat Med. 1998;4(11):1313-1317.

106. Reynolds BA, Weiss S. Generation of neurons and astrocytes from isolated cells of the adult mammalian central nervous system. Science. 1992;255(5052):1707-1710.

107. Treiman DM. GABAergic mechanisms in epilepsy. Epilepsia. 2001; 42(Suppl 3):8-12.

108. Maisano X, Litvina E, Tagliatela S, Aaron GB, Grabel LB, Naegele JR. Differentiation and functional incorporation of embryonic stem cellderived GABAergic interneurons in the dentate gyrus of mice with temporal lobe epilepsy. J Neurosci. 2012;32(1):46-61.

109. Yasuhara T, Agari T, Kameda M, et al. Regenerative medicine for epilepsy: from basic research to clinical application. Int J Mol Sci. 2013; 14(12):23390-23401.

110. Kokaia M. Seizure-induced neurogenesis in the adult brain. Eur $J$ Neurosci. 2011;33(6):1133-1138.

111. Takahashi K, Yamanaka S. Induction of pluripotent stem cells from mouse embryonic and adult fibroblast cultures by defined factors. Cell. 2006;126(4):663-676.

112. Yu J, Hu K, Smuga-Otto K, et al. Human induced pluripotent stem cells free of vector and transgene sequences. Science. 2009;324(5928): 797-801.

113. Shi Z, Zhang J, Chen S, et al. Conversion of fibroblasts to parvalbumin neurons by one transcription factor, Ascl1, and the chemical compound forskolin. J Biol Chem. 2016;291(26):13560-13570.

114. Parent JM, Anderson SA. Reprogramming patient-derived cells to study the epilepsies. Nat Neurosci. 2015;18(3):360-366.

115. Tidball AM, Parent JM. Concise review: exciting cells: modeling genetic epilepsies with patient-derived induced pluripotent stem cells. Stem Cells. 2016;34(1):27-33.

116. Rao MS, Hattiangady B, Reddy DS, Shetty AK. Hippocampal neurodegeneration, spontaneous seizures, and mossy fiber sprouting in the F344 rat model of temporal lobe epilepsy. JNeurosci Res. 2006;83(6): 1088-1105.

117. Shetty AK. Progress in cell grafting therapy for temporal lobe epilepsy. Neurotherapeutics. 2011;8(4):721-735.

118. Jing M, Shingo T, Yasuhara T, et al. The combined therapy of intrahippocampal transplantation of adult neural stem cells and intraventricular erythropoietin-infusion ameliorates spontaneous recurrent seizures by suppression of abnormal mossy fiber sprouting. Brain Res. 2009;1295:203-217.

119. Shetty AK. Hippocampal injury induced cognitive and mood dysfunction, altered neurogenesis and epilepsy: can early neural stem cell grafting intervention provide protection? Epilepsy Behav. 2014;38:117-124.

120. Patrylo PR, van den Pol AN, Spencer DD, Williamson A. NPY inhibits glutamatergic excitation in the epileptic human dentate gyrus. J Neurophysiol. 1999;82(1):478-483.

121. Yasuhara T, Matsukawa N, Hara K, et al. Transplantation of human neural stem cells exerts neuroprotection in a rat model of Parkinson's disease. J Neurosci. 2006;26(48):12497-12511.

122. Scheibel ME, Crandall PH, Scheibel AB. The hippocampal-dentate complex in temporal lobe epilepsy. Epilepsia. 1974;15(1):55-80.

123. Kondo A, Shingo T, Yasuhara T, et al. Erythropoietin exerts antiepileptic effects with the suppression of aberrant new cell formation in the dentate gyrus and upregulation of neuropeptide $\mathrm{Y}$ in seizure model of rats. Brain Res. 2009;1296:127-136.

124. Kanter-Schlifke I, Georgievska B, Kirik D, Kokaia M. Seizure suppression by GDNF gene therapy in animal models of epilepsy. Mol Ther. 2007;15(6):1106-1113.

125. Martin D, Miller G, Rosendahl M, Russell DA. Potent inhibitory effects of glial derived neurotrophic factor against kainic acid mediated seizures in the rat. Brain Res. 1995;683(2):172-178.

126. Li T, Ren G, Kaplan DL, Boison D. Human mesenchymal stem cell grafts engineered to release adenosine reduce chronic seizures in a mouse model of CA3-selective epileptogenesis. Epilepsy Res. 2009;84(2-3):238-241. 
127. Costa-Ferro ZS, Vitola AS, Pedroso MF, et al. Prevention of seizures and reorganization of hippocampal functions by transplantation of bone marrow cells in the acute phase of experimental epilepsy. Seizure. 2010;19(2):84-92.

128. Abdanipour A, Tiraihi T, Mirnajafi-Zadeh J. Improvement of the pilocarpine epilepsy model in rat using bone marrow stromal cell therapy. Neurol Res. 2011;33(6):625-632.

129. Venturin GT, Greggio S, Marinowic DR, et al. Bone marrow mononuclear cells reduce seizure frequency and improve cognitive outcome in chronic epileptic rats. Life Sci. 2011;89(7-8):229-234.

130. Voulgari-Kokota A, Fairless R, Karamita M, et al. Mesenchymal stem cells protect CNS neurons against glutamate excitotoxicity by inhibiting glutamate receptor expression and function. Exp Neurol. 2012;236(1):161-170.

131. Costa-Ferro ZS, Souza BS, Leal MM, et al. Transplantation of bone marrow mononuclear cells decreases seizure incidence, mitigates neuronal loss and modulates pro-inflammatory cytokine production in epileptic rats. Neurobiol Dis. 2012;46(2):302-313.
132. Long Q, Qiu B, Wang K, et al. Genetically engineered bone marrow mesenchymal stem cells improve functional outcome in a rat model of epilepsy. Brain Res. 2013;1532:1-13.

133. Costa-Ferro ZS, de Borba Cunha F, de Freitas Souza BS, et al. Antiepileptic and neuroprotective effects of human umbilical cord blood mononuclear cells in a pilocarpine-induced epilepsy model. Cytotechnology. 2014;66(2):193-199.

134. Leal MMT, Costa-Ferro ZS, Souza BS, et al. Early transplantation of bone marrow mononuclear cells promotes neuroprotection and modulation of inflammation after status epilepticus in mice by paracrine mechanisms. Neurochem Res. 2014;39(2):259-268.

\section{Publish your work in this journal}

Neuropsychiatric Disease and Treatment is an international, peerreviewed journal of clinical therapeutics and pharmacology focusing on concise rapid reporting of clinical or pre-clinical studies on a range of neuropsychiatric and neurological disorders. This journal is indexed on PubMed Central, the 'PsycINFO' database and CAS, and is the official journal of The International Neuropsychiatric Association (INA). The manuscript management system is completely online and includes a very quick and fair peer-review system, which is all easy to use. Visit http://www.dovepress.com/testimonials.php to read real quotes from published authors.

Submit your manuscript here: http://www.dovepress.com/neuropsychiatric-disease-and-treatment-journal 